University of Nebraska - Lincoln

DigitalCommons@University of Nebraska - Lincoln

\title{
Accountability in Networked Governance: Learning from a case of landscape-scale forest conservation
}

Theresa Jedd

Colorado State University - Fort Collins, tjedd2@unl.edu

R. Patrick Bixler

University of Oregon

Follow this and additional works at: https://digitalcommons.unl.edu/natrespapers

Part of the Natural Resources and Conservation Commons, Natural Resources Management and Policy Commons, and the Other Environmental Sciences Commons

Jedd, Theresa and Bixler, R. Patrick, "Accountability in Networked Governance: Learning from a case of landscape-scale forest conservation" (2015). Papers in Natural Resources. 897.

https://digitalcommons.unl.edu/natrespapers/897

This Article is brought to you for free and open access by the Natural Resources, School of at DigitalCommons@University of Nebraska - Lincoln. It has been accepted for inclusion in Papers in Natural Resources by an authorized administrator of DigitalCommons@University of Nebraska - Lincoln. 


\title{
Accountability in Networked Governance: Learning from a case of landscape-scale forest conservation
}

\author{
Theresa Jedd ${ }^{1 *}$ and R. Patrick Bixler ${ }^{2}$ \\ ${ }^{1}$ Department of Political Science, Colorado State University, Fort Collins, CO 80523-1782, USA \\ ${ }^{2}$ Ecosystem Workforce Program, Institute for a Sustainable Environment, University of Oregon, Eugene, \\ OR 97403, USA
}

\begin{abstract}
Despite incredible strides in transboundary collaborative conservation, many challenges remain. A networked governance approach recognizes a diverse pool of participants, linkages across multiple levels of organization and the diffusion of authority horizontally across spatial scales. Much is understood about the basic form and function of networked governance, namely the ways in which it overcomes weaknesses of traditional hierarchical structures, but less is known about the democratic quality of newer forms of governance. There are implications for traditional forms of accountability for the practice of network governance. They are not lost but their dimensions are changed, hinging less on punishment and more on reward. To examine this dynamic, we use a mixed-methods approach and grounded theory to explore the social relationships that make up a conservation network in the United States and Canada. Interview analysis from the Roundtable on the Crown of the Continent suggests that accountability comes through authentic engagement, is based on a 'logic of appropriateness' rooted in normative persuasion and still draws from traditional hierarchy. Social network analysis shows positions of brokerage and bridging help to maintain network connections between actors. Leveraging these characteristics of the network and the relationships formed through the process of landscape forest governance, we suggest there may be an overall net gain in accountability. Copyright (C) 2015 John Wiley \& Sons, Ltd and ERP Environment
\end{abstract}

Received 7 January 2014; revised 12 October 2014; accepted 20 October 2014

Keywords: accountability; collaborative governance; networks; social network analysis; transboundary conservation

\section{Introduction}

NVIRONMENTAL PROBLEMS ARE THE RESULT OF COMPLEX SOCIAL-ECOLOGICAL INTERACTIONS AFFECTING DIVERSE SECtors and interest groups across multiple levels of organization (Berkes et al., 2003; Armitage et al., 2009). The past two decades have witnessed shifts in the institutions designed to address environmental problems at local, regional and international levels. Scholars have noted the relocation of authority up, down and

*Correspondence to: Theresa Jedd, Department of Political Science, Colorado State University, Fort Collins, CO 80523-1782, USA. theresa. jedd@colostate.edu.

E-mail: theresa.jedd@colostate.edu 
around the state, with varying degrees of public and private involvement spanning jurisdictions (Rhodes, I996; Rosenau, 2002). These newer governance forms are sometimes referred to as instances of adaptive co-management (Olsson et al., 2004), polycentricity (Ostrom, 20I0; Bixler, 20I4) or multi-level governance (Betsill and Bulkeley, 2006). We find it most useful to characterize these new forms as networked governance (NG), emphasizing linkages between actors in environmental governance. It is commonly argued that NG provides flexibility to better fit social demands and ecological problems.

A networked governance approach addresses the challenges posed by complex environmental problems spanning intrastate jurisdictional lines and international borders by building in an explicit recognition of the mixed composition of governing entities as well as a shifting fundamental logic of governance. Other approaches share the recognition that civil society and private actors are indispensable in addressing ecological problems, but NG provides a lens to focus on the characteristics of the relationships between actors, individuals and organizations. This fits with the call to action in the earth system governance research framework highlighting the need to better understand the changing role of actors, organizations and institutions in shaping governance (Biermann et al., 2010). An NG approach is also congruent with other emerging frameworks that focus on the social dimensions of environmental governance (Sandström et al., 2014).

This greater attention to governance arrangements as configurations of relationships between people, however, uncovers new barriers and problems that are the result of social interaction. In particular, according to Biermann and Gupta (20II), current earth system governance lacks accountability. If emerging forms of governance are to be functional and sustainable, this must change. Networks often take on large membership numbers, pulling from both broad spatial and sectoral reach, making it difficult to assign blame for failure in NG. Because networks lack a hierarchical authority structure, it is sometimes unclear who is responsible for making decisions or stepping in when those decisions result in negative outcomes.

The research presented here focuses on the dimensions of accountability in the relationships that form between governing entities across multiple resource issue areas, which at the international level refers to 'institutional interplay' (Young, 2002). This third wave of research recognizes that an institution's impact does not result from singular efforts, but from the influence of other overlapping institutions. Governance, under this perspective, can be compared with 'a layered quilt of explicit and implicit rules and norms that emerge from international, national, subnational, and local levels' (Mitchell, 2013: 6). It is in this space of institutional interplay that we address the challenges of accountability in networked environmental governance.

Here we identify a particular network where self-organized governance arrangements have resulted in new patterns of authority and accountability. Rather than ask whether accountability is present or absent, or if NG results in 'more' or 'less' accountability, we examine the ways accountability has been altered. Our contribution lies in the proposal that accountability does not hinge on redress, but instead on the ability of a broad group of individuals to positively engage each other. We suggest that diffuse authority does not have to mean that accountability is lost; rather, its dimensions are changed. Through the lens of 'networked governance', accountability is broadened. More specifically, we find this means that:

I. accountability comes through authentic engagement;

2. accountability is based on a 'logic of appropriateness' that utilizes normative persuasion - consequently, accountability takes on more of the characteristics of reward than redress;

3. accountability still draws from traditional hierarchy as a significant portion of authority still rests in the state;

4. and positions of brokerage and bridging play an important role in maintaining the above connections.

In NG, accountability is grounded in social relationships. We will explore this by illustrating the claims above. First, we consider the theoretical background of NG and accountability in the transboundary context. We then introduce our case. We next present our research methods, based on an analysis of network surveys and qualitative interview data. We offer results in a discussion format, focusing on the theoretical contribution of accountability as applied to our case in the Crown of the Continent. We conclude by revisiting the four major dimensions of accountability. 


\section{Theoretical Background: the Rise of NG and Accountability}

\section{Networked Governance}

NG relies on a blend of public and private actors along with the emergence and growth of 'flatter', 'self-organizing networks of societal actors' (Jordan, 2008: ०००), suggesting not only that we are trending towards a world in which decisions are made by more than just states, but that the fundamental patterns of authority in governance are changing. In this context, there is an increasing recognition of the need to look beyond disciplinary boundaries and technical approaches and engage a variety of stakeholders in solving complex problems (Dietz et al., 2003; Folke et al., 2005; Bodin and Prell, 20II). This implies a move from political administrative hierarchy to collaborative structures (Koppenjan and Klijn, 2004; Olsson et al., 2004). This paradigm shift implies management is less formal, more flexible and more adaptive (Carlsson and Berkes, 2005; Bodin and Crona, 2009; Newig et al., 20I0). Institutions should draw upon multiple social domains, incorporating diverse knowledge systems with a focus on continuous learning (Dietz et al., 2003; Keen et al., 2005; Armitage et al., 2009; Crona and Parker, 2012). In addition to learning, flows of resources and information are increasingly the focus of environmental governance research (Bodin and Crona, 2009; Lewis, 20II; Robins et al., 20II).

As an alternative to political-administrative hierarchy, the study of governance arrangements often assumes the involvement of social networks (Carlsson and Sandstrom, 2008). These inter-organizational networks are characterized by repetitive exchanges among semi-autonomous organizations that rely on trust and embedded social relationships to protect transactions and reduce their costs (Powell, I990). Networks create value (Büchel and Raub, 2002) and accumulate vital resources and power (Pfeffer and Salancik, I978) needed to carry out shared tasks. Furthermore, certain network characteristics also influence an organization's ability to recognize and respond to environmental change (Kraatz, I998). Networks are important for natural resource governance that fosters cross-scale adaptive capacity (Bodin and Crona, 2009; Bodin and Prell, 20II). This adaptive capacity stems largely from the linkages between individuals and organizations (Carlsson and Sandstrom, 2008), with social connections serving as a realistic way to address complexity in environmental governance (van Bueren et al., 2003).

At their core, 'networks [are] diffuse, complex and weakly institutionalized collaborative systems are neither directly accountable to an electoral base' (Benner et al., 2004: ०००). Our evidence suggests that even if electoral accountability and hierarchical accountability are both lacking in networked arrangements, the diffuse nature of authority actually implicates a broader host of actors equipped to call attention to and request redress for mistakes. This point is particularly salient when conservation actions are aligned across large spatial scales. Establishing and maintaining partnerships, identifying shared objectives and spatially coordinating conservation are substantive governance challenges (Wyborn, 20I4). Accountability mechanisms intended to connect local to regional scales are necessary to coordinate and implement actions across ecological and jurisdictional scales in spatially distributed networks. This requires an iterative exchange based on cross-border partnerships between managers and resource users (Berkes, 2004), best facilitated through a network of public, private and civil society actors (Mason, 2005, 2008).

\section{Accountability in the Transboundary Context}

Accountability involves judging the actions of others based on a set of criteria regarding acceptable behaviour. Grant and Keohane (2005: 29) offer that accountability 'implies that some actors have the right to hold other actors to a set of standards, to judge whether they have fulfilled their responsibilities in light of these standards, and to impose sanctions if they determine that these responsibilities have not been met.' It means actors in a governance scheme possess the authority to demand redress for wrongdoings or harmful behaviour. In the international transboundary context, this comes when authority is truly diffused or fragmented (Biermann et al., 2009; Zelli and Van Asselt, 20II). Accountability in the strict legal sense simply does not exist as it does at the national or sub-national levels. At the domestic level, the courts often enforce legal institutions. This process allows affected individuals and groups to register complaints and be compensated for damages. Judicial bodies at the international level, however, are plagued with problems related to opt-out and the barrier of state sovereignty. 
Furthermore, it is difficult to establish the body of individuals and/or organizations that are entitled to participate in international processes. There are numerous 'global publics' and it is difficult to garner fully democratic participation at the global level (Dryzek, I999; Risse, 2006). For these reasons, we move away from a strict legal conception of accountability suggesting, in the absence of formally democratic institutions or binding legal agreements, accountability for environmental protection has been achieved through alternative mechanisms. We adopt a realistic perspective on the limitations of these informal obligations actors have to one another, acknowledging that the type of informal accountability found in NG is complementary to traditional legal mechanisms for redress, rather than a replacement.

\section{Research Context and Case Description}

The Crown of the Continent landscape in north-west Montana is a socially and ecologically diverse area covering approximately I 8 million acres. It includes the protected areas of the Bob Marshall wilderness and Waterton-Glacier International Peace Park (Figure I). A world-class mountain eco-region, it is home to many endangered and rare species, including grizzly bears, wolves, lynx and bull trout. Public lands comprise $83 \%$ of the Crown of the Continent Ecosystem managed for multiple uses, including recreation, biodiversity, water supply, timber extraction, energy development, and fish and wildlife habitat (Prato and Fagre, 2007). National, state/provincial, municipal and private lands make up the varied ownership and management jurisdictions. These variegated ownership patterns pose management challenges: the 'jurisdictional fragmentation' makes for complications because management at the landscape level requires cross-agency collaboration (Prato and Fagre, 2007). In addition to the ecological integrity and connectivity of the landscape, there is also strong momentum to maintain the rural cultural and social fabric of regional economic livelihoods and traditional practices characterized in rural communities and tribal nations. This rich context makes it an ideal region for experimenting with landscape conservation initiatives.

Organizationally, landscape conservation is a new approach to cross-boundary environmental governance and the Roundtable on the Crown of the Continent plays an interesting role (Wyborn and Bixler, 20I3). The 'Crown Roundtable' is a collaborative conservation project in its fourth year of bringing together a diverse body of participants who all share a basic desire to conserve the landscape that stretches from north-western Montana, south-eastern British Columbia into south-western Alberta. It fits with the ways NG is described in the literature in that it was not designed to be a forum for formal decision-making, but rather a space for informal collaboration. The Roundtable aims to minimize the distance between organizations, agencies and individuals interested in conservation. Although it has only been in place since 20I0, with more than Ioo participants spanning the public and private sectors, this 'network of networks' has already built an impressive foundation for connecting a wide variety of interests in one of the most intact and pristine landscapes in Northern America (Prato and Fagre, 2007; McKinney, 20II).

Landscape-level NG simultaneously scales up and scales down forest governance. It scales down from the globallevel United Nations Forum on Forests' 'Forest Principles' and far-reaching international agreements on sustainability reporting. It scales up smaller conservation efforts by linking them at the larger landscape level. For the Crown of the Continent Ecosystem, for example, smaller private groups such as the Blackfoot Challenge and the Water Matters Society of Alberta have already united divergent interests (Bixler and Taylor, 20I2). These formerly independent networks must now think about how their interests fit within the even larger geographical, ecological and political scales. Landscape-level conservation provides an opportunity to 'think regionally, but to act at whatever scale makes sense' ('Roundtable on the Crown of the Continent', 20Ir: ০০০). This innovative solution could provide a way out of a global cycle of deforestation and resource depletion by uniting diverse actors and interests around the common identity of a landscape.

\section{Methods}

This research adopted a mixed-method case study approach. Case study research is used to corroborate or falsify existing and new concepts or theory (Yin, 2003). Here we use accountability as the analytical object of inquiry 


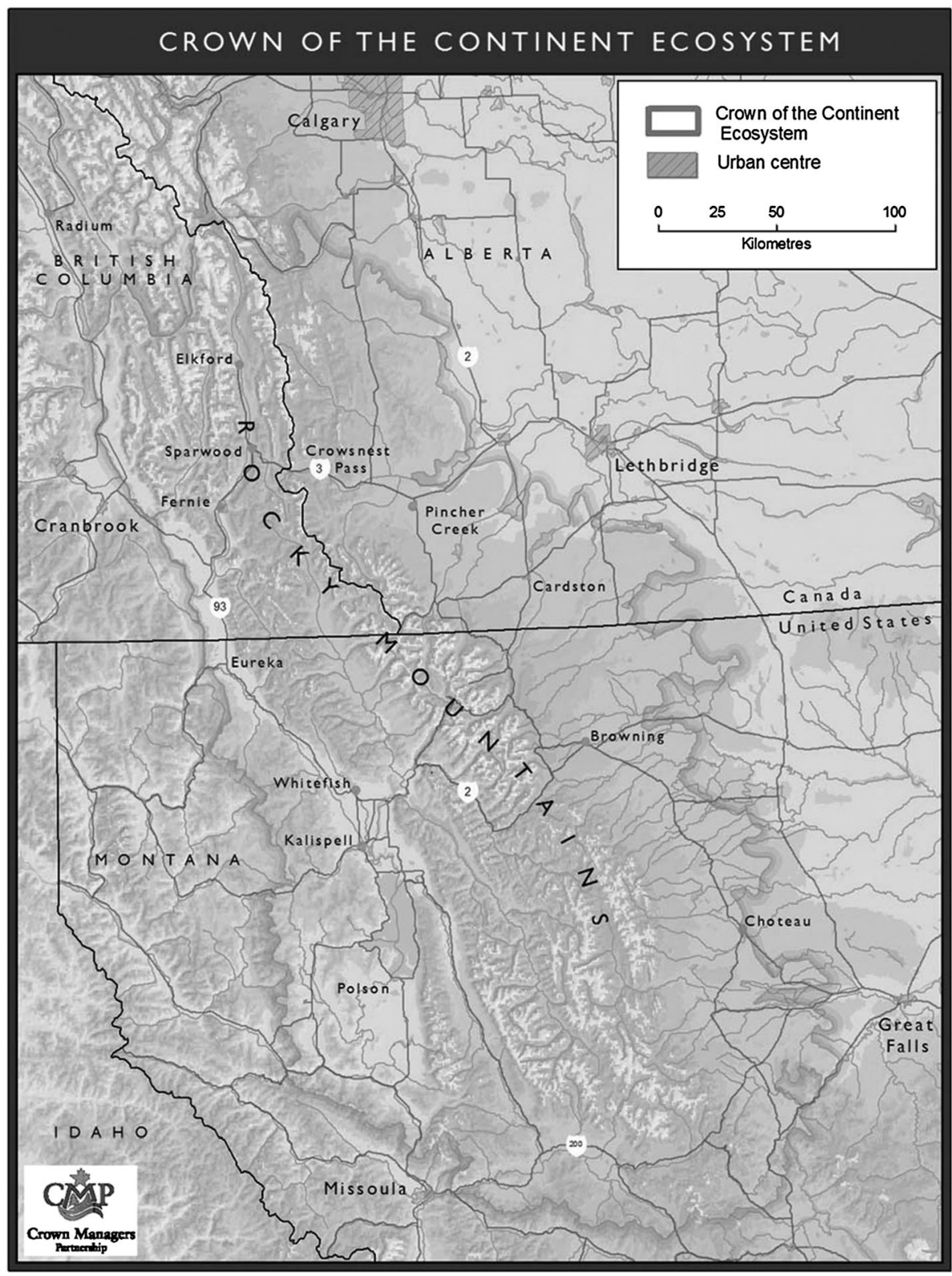

Figure 1. Crown of the Continent map. Courtesy of Crown Managers Partnership.

(Yin, 2003). In-depth understandings of one case can be used to explore or validate broader phenomena (Charmaz, 2006). Moreover, our inquiry fits with grounded theory in that we used repetitive cycles of examining data and building theory (Charmaz, 2006). We use two methods to support this grounded case study approach: social network analysis (SNA) and qualitative interviews.

\section{Combining Network and Qualitative Data}

The investigation began in September 2012 with 2 months of participant observation and interviews, followed by another period from January 2013 to April 20I3. We combined SNA with qualitative field research methods. Substantial benefits have come from combining SNA with interviews, ethnography and historical research (Cross et al., 2009), adding the context to help interpret network data (Bellotti, 20I4). While SNA produces an outside view 
of the network structure, in-depth interview data add to an inside view, with closer attention to the content, quality and meaning of network ties. Mixing methods also provides a focus on dynamics, highlighting the less visible dimensions not always apparent in the structure. The central objective of combining network analysis and qualitative inquiry is to represent those structural relations accurately but also to explain why they occur and their consequences.

\section{Network Data Collection and Analysis}

SNA proved to be valuable as it identified nodes, linkages and sub-groups. Nodes represent organizations in the network, links are the relationships between them and sub-groups are the smaller communities within the network. To capture the ties among stakeholders, we developed and implemented an online survey. This survey was sent to all interview participants and the 2013 Crown of the Continent Roundtable attendees. It used a name generator (Knoke and Yang, 2008) where the respondent listed up to Io organizations.

In total is people responded to the organizational survey, representing $\mathrm{I} 6$ organizations. Participants named four additional organizations that were not otherwise represented, resulting in a missing data rate of $2 \mathrm{I} \%$. Others have found network surveys generate missing data (Burt, I987; Borgatti and Molina, 2003; Kossinetts, 2006). However, insights are derived from whole network analysis, and imputation procedures have been used and justified to replace the missing values of a non-respondent with the values of the respondent (Andridge and Little, 20IO). Imputation or reconstruction replaces missing ties with values reported by responding actors (Burt, I987). In environmental governance research, missing data up to $20 \%$ is generally accepted (Bodin and Prell, 20II).

The survey asked respondents for names of individuals/organizations they gave or received information regarding climate adaptation in forest conservation. These non-directional data indicate two organizations share information with each other, but do not necessarily specify the giver or receiver. In the network diagram maps displayed below, the arrows of directionality illustrate the responding organization. The nodes in the maps are the organizations and the edges represent reported links between them.

Our network analyses were conducted using Gephi, an open-source, free network analysis and visualization platform. The software allowed us to interactively display nodes in various spatial configurations, harnessing not only a quantitative set of standard algorithms for network statistics but also the ability to visualize the data. To a large extent, our ability to recognize new patterns of engagement in the networks depended on being able to display them (Bastian et al., 2009).

We use two measures of the social network analysis to structure our argument: modularity (network level) and betweenness centrality (node level). Modularity, or community structure, is the appearance of densely connected groups of vertices, with only sparser connections between groups (Newman, 2006; Figure 2). The modularity function in Gephi uses the algorithm from Blondel et al. (2008).

Betweenness centrality, another useful measure, reports a dimension of centrality (Freeman, I979). When certain actors have a disproportionate number of ties compared with other actors, one generally concludes that these

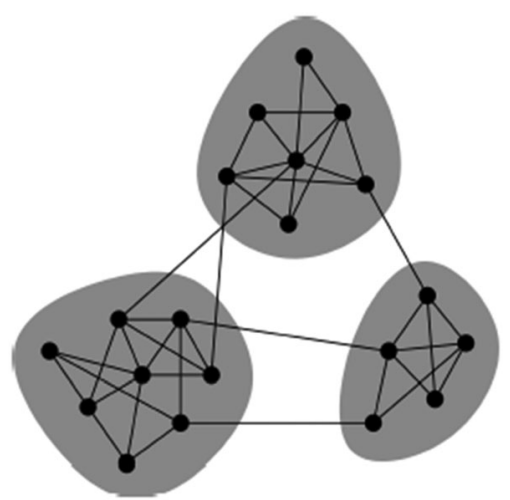

Figure 2. Bridging edges. The nodes in many networks fall naturally into groups or communities, sets of nodes (shaded) within which there are many edges, with only a smaller number of bridging edges between nodes of different groups. The shaded area represents different network 'communities'. Adapted from Newman (2006). 
actors are more central to the network. Betweenness centrality measures how much potential control an actor has over the flow of information by taking into account the shortest path between two actors by identifying individuals located in between (see Burt, 2005). An actor's score increases with the number of times that actor rests on the shortest path between two actors. If an actor rests between many others in the network, they may have more influence. Gephi uses the betweenness centrality algorithm of Brandes (200I). The full network map is shown below in Figure 6, and some basic network-level and node-level statistics are included - in Table I.

\section{Qualitative Data Collection and Analysis}

The fieldwork included two interrelated methods, participant observation and interviewing (Yin, 2003). Our approach was grounded in ethnographic research where immersion, frequent visits and participant observation establish trust between the researchers and respondents, building a depth of knowledge for people, their activities and places (Creswell, I998). We began our interview sample with established contacts in the Crown Roundtable. We used a purposive snowball technique asking participants to provide names of others with valuable perspectives (Yin, 2003). The interviews, which ranged from approximately $40 \mathrm{~min}$ to $\mathrm{I} .5 \mathrm{~h}$ in length, were digitally tape-recorded and transcribed verbatim to permit detailed coding (Strauss and Corbin, I998). In total, we conducted interviews with 79 participants. Interviews were transcribed, coded and grouped by theme in NVivo Io qualitative analysis software. Interview data provide context for survey data, particularly regarding understanding how participants perceived their involvement and others engaged in the collaborative process. The complementary nature of survey and qualitative data allows a better understanding of network dynamics (Cross et al., 2009).

\section{Results and Discussion}

\section{Accountability as Authentic Engagement}

Most significantly, a new meaning of accountability is emerging in network governance. We see authentic engagement when citizens and stakeholders move from the traditional 'provide input and advice' model to shared framing of issues, generating options, making decisions and implementing solutions (Carlsson and Sandstrom, 2008). As one key participant, a biologist at a Montana research station states, 'We try to do things voluntarily, willingly, collaboratively, sharing information, exporting strategies that are successful to the region and where it makes sense to all work together to make something happen collectively.' The heightened sense of responsibility in authentic engagement goes beyond providing information, or serving as a point of contact, towards creating a shared vision. In another's words, the process of authentic engagement in planning and visioning is distinct from the administrative process of developing binding management protocols:

The advice that I've given to the Roundtable consistently is: 'don't attempt to even think about discharging the jurisdiction or coming up with protocols or agreements.' If you're a network of networks, then the intent is to get the greatest possible alignment between those components of the network.

This sentiment was repeated across multiple interview participants, namely that the process of aligning interests and efforts has an added value to traditional management public planning processes. This authentic engagement is

\begin{tabular}{lc}
\hline Total nodes & 16 \\
\hline Total edges & 36 \\
Density & 0.235 \\
Average degree & 2.11 \\
\hline
\end{tabular}

Table 1. Descriptive network statistics 
made possible by bringing individuals and organizations together in workshops, field visits, and even dinners and social events. This form of engagement hinges on frequent and sustained communication. One particular Roundtable programme, the 'Adaptive Management Initiative', has facilitated a process of sustained communication between grantee organizations with monthly learning phone calls and webinars. As the modularity analysis indicates, these organizations have developed a sub-group within the network of organizations, representing 50\% of the total network surveyed (Figure 3, module I of the whole network).

The ability to detect such groups could be of significant practical importance for accountability in NG. Finding that a network contains tightly knit groups at all can convey useful information: if a social network were divided into such groups, for instance, it could provide evidence for a modular view of the network's dynamics, with different groups of nodes performing different functions with some degree of independence.

Authentic engagement entails a foundation of social relationships. This is particularly important given that, as noted elsewhere, successful natural resource governance 'is one where actors, during periods of stability, develop new relational ties with various other actors and stakeholders which can be drawn upon in times of change' (Bodin and Crona, 2009: 372). As one participant put it, the Roundtable is successful because the various organizations

are completely open and trust each other, we know how to delegate different aspects of the work to the appropriate organization and no one's really concerned about the ego gratification, we're all concerned about the outcomes, so it's not about taking credit, it's about getting results.

In some ways, this authentic engagement is driven by the financial support that the Roundtable provides to grantees of the Adaptive Management Initiative. Through the process of granting projects, the Roundtable has also developed a cohort of groups invested in sharing information, using the platform of the Roundtable as a connecting hub. Through this process, participants interact and share information.

\section{Accountability under the 'Logic of Appropriateness': rewards rather than redress}

In networks, a 'professional/peer' accountability hinges on adhering to a code of conduct (Benner et al., 2004) or set of norms, or maintaining an appropriate identity. It is based on the logic of appropriateness, rather than the logic of consequences grounded in a rational calculation of costs and benefits. The reward for adhering to a particular standard is the creation and maintenance of professional relationships in which resources and information are exchanged. Participants mentioned how their work in the Crown Roundtable, specifically when they heard about how others were monitoring ecological conditions, would motivate them to return to their own organizations with renewed motivation to set targets and thresholds, along with information on others' best management practices. As one interviewee put it, because individuals and organizations are working together in the network:

We're proposing something called a transboundary management protocol: modeled on something we're doing in Alberta with regional planning in a big chunk of the province. And we've adopted in recent years a cumulative effects management system, being renamed integrated resource management system.

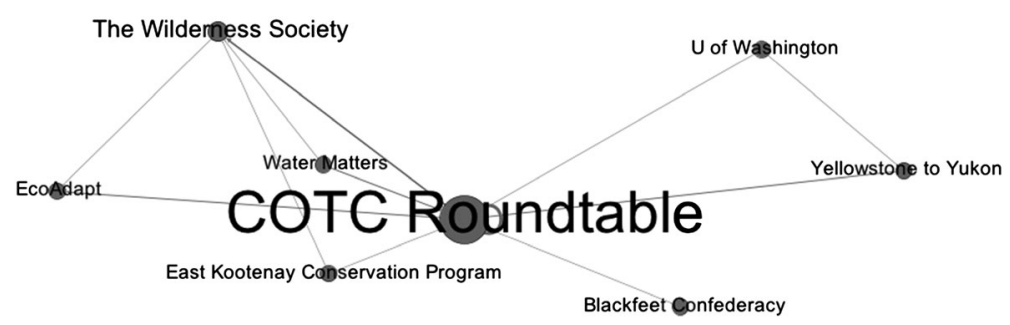

Figure 3. Network analysis module 1 representing $50 \%$ of the network. These organizations are directly engaged in the Adaptive Management Initiative facilitated by the Crown of the Continent Roundtable, or are partners directly involved with projects. Size of node and label for each organization is proportional to betweenness centrality scores. 
This type of information exchange can lead to a particular logic of acting, which itself entails a dimension of accountability organized around shared norms. As one community organization's director put it, when the Roundtable process began, 'We just spent a day together, talking about the information, getting to know each other, talking about the Flathead, but not just the Flathead - talked about the issues that we were facing.' These shared norms may come about through repeated interactions.

Accountability in NG interactions does not come from a sense of forced compliance. This theme was repeated across interviews. Another research participant from a local chapter of a national NGO remarks:

We overlap in places and those places where we overlap we should leverage where we can but those places we don't we shouldn't force it. We certainly shouldn't tell each other what to do, but there is some peer pressure that here is where the collaborative is going and 'I better be on board'.

When accountability does not operate under the auspices of redress, participants are accountable to each other because they are rewarded with information and resources they may otherwise not have access to. Modularity analysis of the network highlights this reward of information dimension in two places, modules 2 and 3. Module 3, according to the network analysis, represents two organizations - the Flathead Basin Commission (FBC) and the Confederated Salish and Kootenai Tribe (CSKT), or I2.5\% of the network; see Figure 4.

Module 2 includes three non-governmental organizations (NGOs) that are geographically large: the Crown Managers Partnership, the Crown of the Continent Conservation Initiative, and the Heart of the Rockies (Figure 5).

In modules 2 and 3, we find organizations with a history of collaboration. These particular subgroups have developed a set of norms and identity among themselves. Staff from the FBC made remarks to this:

If you think about me, I'm in a bunch of different groups and they are not concentric circles they are overlapping circles. I'm on the Flathead Basin Commission dealing with aquatic invasive species ... So you start to see a lot of similar players in different organized environments working on the same issue ... There are 80 different groups and there is overlap of these groups.

For the FBC, the CSKT has been a key strategic partner in the southern portion of the Flathead watershed for the FBC to achieve its mandate to monitor and protect water quality of the Flathead Basin. These social relationships build a degree of accountability between the organizations.

A member of another group, the Heart of the Rockies initiative, talks about what constitutes reward for interacting and exchanging information:

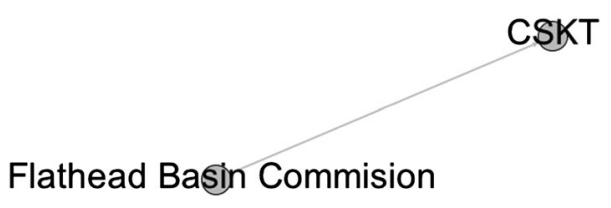

Figure 4. Network module 3. The Confederated Salish and Kootenay Tribe (CSKT) and the Flathead Basin Commission.

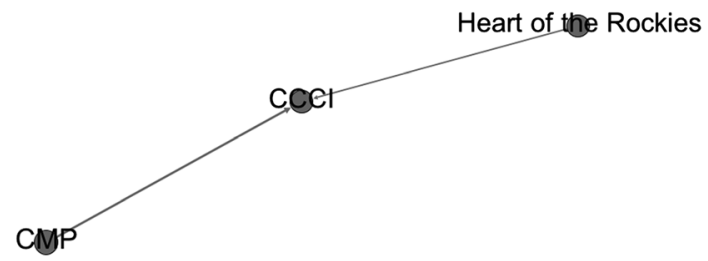

Figure 5. Module 2: Crown Managers Partnership (CMP), the Crown of the Continent Conservation Initiative (CCCI) and the Heart of the Rockies. 
There are 25 organizations that are a part of that [Heart of the Rockies]. Most of what I get out of that [as a member] doesn't happen at those formal meetings. What I get out of the formal meetings is get to know who these people are. Get to build a personal relationship with them. I hang out for two days, I eat breakfast with them, I get to know them. I get to find out what kind of projects they are working on ... Afterwards is when we collaborate on a project.

Across the landscape, conservation practitioners face similar challenges and the network offers the opportunity to tap into and embed within the larger context. The development of a norm of information exchange, and the dimension of accountability that comes with it, can spread throughout the network, as the next section indicates.

\section{Accountability in the Peer-Based or Relational Context: Drawing on Traditional Authority}

Without a clear chain of command or established rules of transactions, actors sometimes wonder whether their organization is the proper locus of action, or if they have the authority to act. In some cases, networked arrangements can develop formal protocols that enact more traditional (hierarchical) mechanisms of accountability. Management protocols may eventually be codified in Memoranda of Understanding (MOU), which are more formal outgrowths from the network arrangement. As an environment ministry official put it, the MOU is a statement about 'an accountability that is, you know, it's your signature, you know. It's "we're serious" or "we're not serious".' These formal agreements can provide some obligation to informal network arrangements, particularly when traditional state-based authorities use them. Furthermore, interviewees indicated an understanding that state-based entities retain ultimate decision-making authority. As one Parks Service representative put it, 'The partnership doesn't manage, the agencies do ... We kind of each have our mandates, our missions, but we sit at the table.' Many of our interviewees confirmed that networked actors come together knowing that the ultimate control resides with their agencies, their constituent voters and/or the landowners within the ecosystem.

Network agreements, however, are embedded in these other formal processes. For example, resolution of riverbed contamination due to mining activities in British Columbia has been achieved through hierarchical mechanisms - namely, transboundary agreements between provincial and state authorities. Using a hierarchical form of accountability was arguably only possible for NGOs through networked relationships across the international border.

In both government and civil society, actors stated that using water quality standards in the US was effective for influencing resource extraction in Canada. In this sense, accountability becomes layered. The particular mechanism in this instance was an MOU between the British Columbia Premier and the Montana Governor that placed a moratorium on mining activities in British Columbia that were negatively impacting water quality in Montana. In the Elk River Valley, conservation practitioners expressed frustration with stream contamination in forested areas because of coal mining operations. Selenium run-off from metallurgical coal mining posed ecological threats but a mining operation refused to respond to NGOs' requests to reduce tailings. The provincial natural resource agencies lacked regulatory oversight, and were therefore ineffective at curbing threats to water quality. However, the NGOs in British Columbia were able to work with US federal agencies in Montana, including the FBC, to enforce regulations on water quality in streams flowing into US territory. Without the broadened and diffuse pattern of authority and the relationships spanning beyond the Elk River Valley community, civil society might have been ineffective in holding the mining company accountable. This MOU was made possible by the cooperation of individuals across borders, and then becomes a tool that facilitates further cooperation. International relations scholarship points out that we might expect this, given that networks are often embedded within others (Galaz et al., 20I4).

\section{Hubs and Brokers of Accountability}

Social hubs and nodes are important 'hinges' in network accountability. These positions of brokerage are literally 'in-between' the formal and informal dimensions of accountability. We illustrate this by linking all modules together to derive the full network map, as illustrated in Figure 6. In our case, the main partnership-building organization, the Roundtable on the Crown of the Continent, plays a significant role as both a social hub and a broker, as defined by total degree and betweenness centrality, respectively. 


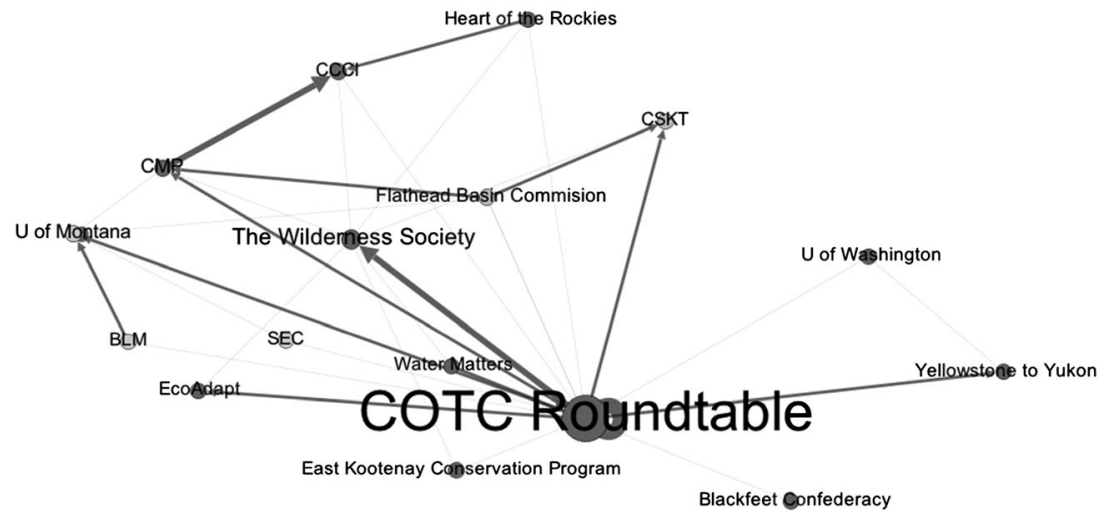

Figure 6. Combined network map of all four network modules. Size of node and label for each organization is proportional to betweenness centrality scores.

Certain nodes play a strategic role in their level of centrality in the network. Table 2 lists the top seven organizations ranked by betweenness centrality.

We see that while certain organizations might not be linked directly to others, they are linked through other connecting nodes. These linkages can take on 'fanned' or circular patterns (Figure 7). Fanned patterns are formed when a particular organization maintains a relationship with many others. Circular patterns place less burden on any one particular organization and look more like a chain - here, the chain loops back around to form a circle,

\begin{tabular}{lcc}
\hline Respondent & Betweenness centrality & Modularity \\
\hline Crown of the Continent Roundtable & 74 & 1 \\
The Wilderness Society & 9.16 & 1 \\
University of Montana & 2.5 & 4 \\
Crown Managers Partnership & 1.83 & 2 \\
Flathead Basin Commission & 0.83 & 3 \\
Crown of the Continent Conservation Initiative & 0.33 & 2 \\
Confederated Salish and Kootenai Tribe & 0.33 & 3
\end{tabular}

Table 2. Organizations ranked by betweenness centrality. Only organizations with a betweenness centrality score $>0.01$ are listed

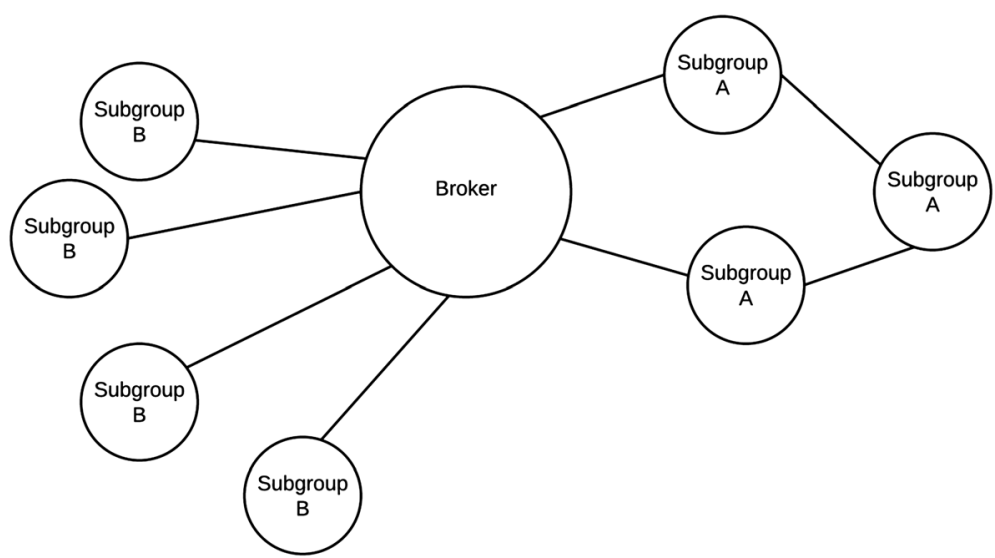

Figure 7. Configured representation of a subset of the Crown Roundtable Network showing a 'fanned' pattern from the broker on the left and circular pattern on the right. 
bringing a handful of organizations that are not directly linked into a loop. In these cases, the organizations that do the connecting may be more influential in the network (Long et al., 2013).

Both social network and qualitative analysis suggests the Roundtable on the Crown of the Continent plays a significant brokerage role in the network. We use two main indicators to highlight this, betweenness centrality and total in-degree (Table 3). As indicated in Table 2, the Roundtable has a betweenness centrality score of 74, over eight times more central than the next highest organization (The Wilderness Society, 9.I6). The network analysis results also illustrate the importance of the Roundtable with an in-degree of 9, with $40 \%$ more incoming ties than the next organization. 'In-degree' is a measure of how many ties are received by a node and is an indication of a node's prestige (Wasserman and Faust, I994). Prestige increases when the actor becomes the object of more ties, but not necessarily when the actor itself initiates the ties. The sender-receiver or source-target distinction strongly emphasizes inequality in control over resources, as well as authority and deference accompanying such inequalities (Knoke and Burt, I983). The literature suggests that positions of brokerage and prestige have disproportionate influence and power over the network given their unique structural position, and our evidence suggests part of this influence is catalysing the different dimensions of network accountability.

Our qualitative evidence supports this notion, too. For example, a community-based practitioner who works on public lands outside Glacier National Park reflects on this broker role of the Roundtable:

You have these conveners like the Roundtable that have the potential to serve a really interesting purpose in terms of being a marriage broker to tie people with like interests to one another and finding overlapping interests that you might not have known existed.

One of the main ways of convening overlapping interests is the annual multi-stakeholder forum at the Roundtable on the Crown of the Continent (the 5th annual Roundtable was held in Waterton Lakes National Park, Alberta, in September 20I4). The stated, intended outcomes of the annual meetings are to shape the collaborative dialogue, coalesce around regional objectives and set the policy direction for the network. Our purpose here is to unpack the unintended outcomes of the Roundtable process. In hosting the meetings and encouraging open and inclusive participation, the Roundtable is working to engage stakeholders authentically. By setting the agenda, scheduling time for interaction and information sharing, and cultivating a common vision for the future of the Crown of the Continent landscape, the Roundtable is establishing particular norms of the network. Through this central position in the network, the Roundtable is practising many of the dimensions of network accountability we discuss.

\begin{tabular}{lcc}
\hline Organization & In-degree & Out-degree \\
\hline Crown of the Continent Roundtable & 9 & 12 \\
University of Montana & 6 & 1 \\
The Wilderness Society & 5 & 4 \\
Crown of the Continent Conservation Initiative (CCCI) & 4 & 0 \\
Confederated Salish and Kootenay Tribe (CSKT) & 3 & 0 \\
Yellowstone to Yukon & 3 & 1 \\
Crown Managers Partnership (CMP) & 2 & 3 \\
EcoAdapt & 2 & 0 \\
Blackfeet Confederacy & 1 & 0 \\
Flathead Basin Commission & 1 & 4 \\
Bureau of Land Management (MT BLM) & 0 & 2 \\
Heart of the Rockies & 0 & 3 \\
Swan Ecosystem Center (SEC) & 0 & 2 \\
Water Matters & 0 & 2 \\
University of Washington & 0 & 2 \\
East Kootenay Conservation Program & 0 & 2 \\
\hline
\end{tabular}

Table 3. In-degree and out-degree of each organization 
Moreover, in network terms the Roundtable has direct ties to every subgroup identified in the modularity analysis and by doing so connect different subgroups or network modules. When these organizations bridge communities, they act as 'hinges' in network structure connecting otherwise disconnected groups and thus promoting innovation and learning and providing opportunities for emergent leadership and collaborative innovation (Crona and Parker, 20I2). Through these connections, the brokerage organizations 'practise' authentically engaging and establishing norms of interaction and information sharing and thus play an important role in the broader network processes of accountability. Note also that brokers in the network play a role in connecting organizations where they collaboratively explore avenues for traditional recourse, as illustrated in our case study.

\section{Conclusions}

We have identified four key dimensions of accountability in NG. These dimensions hinge to a large degree on the fundamentally social nature of NG, i.e. NG is dependent upon the relationships that actors and organizations have with one another. These findings support the notion of 'pluralistic accountability', which is based on actors, processes and outcomes (Benner et al., 2004). Furthermore, the nature of these relationships matters a great deal for actors' ability to hold one another accountable. In an era of unprecedented global environmental change, the promise of NG is that it provides more flexibility than traditional forms of governance by layering with other mechanisms. We propose that in NG a new conceptualization of accountability is warranted that has four essential dimensions:

I. it requires authentic engagement;

2. it is based upon norms developed through interaction and sharing information;

3. it sometimes requires leaning upon traditional forms of recourse where the authority still rests with the state;

4. it uses brokers as catalysts of accountability.

Establishing collective network mission and goals is critical for accountability, and hence the importance of meaningful engagement of network members. As the network collectively moves towards those goals, and as the network relationships grow stronger, accountability in the network is enhanced.

Note that our case study is a successful case of network governance. Initiating an NG initiative will not automatically produce a net gain in accountability, and there are instances where too much accountability causes networks to dissemble (Imperial, 2005). Yet, in our case these layers of accountability motivate network organizations to engage and participate in network processes. There are many variables that make NG successful (Scarlett et al., Forthcoming), and our case was an example of many of the important factors, including strong agency and non-agency leadership, conservation funding in the region, aligned motivations and desired conservation vision.

However, even in our case, this is not to say that accountability in NG is not complicated. There is evidence to suggest that, at times, providing information is as far as participants are willing to go when collaborating on controversial issues. Participants shift from feeling responsible for decisions back towards a more 'hands-off' role of providing information or giving advice. For example, interviewees suggested that with contentious issues such as aquatic invasive species, the provision of information was as far as agreements could reach. In other instances, it seems that litigation will continue to be a part of the governance process on the landscape. Further work might thus consider the ways that the feeling of responsibility or engagement could be diminished in challenging times of disagreement.

It is generally recognized that it is neither feasible nor desirable to create an overarching, hierarchically ordered governing scheme at the global level for forests. To begin, the possibility of creating a binding global governing body in any issue area is limited, let alone forest management. Land tenure claims, and the management decisionmaking to which they are tied, tend to remain at national or subnational levels. Because of this complexity, it stands to reason that an overarching agreement related to forests may not ever be reached. However, these mechanisms are not the only options for accountability. Through networks, we have identified additional layers of accountability that go beyond the traditional hierarchical ones that we are generally more likely to identify. 
This suggests the lack of formal treaty-level agreements does not represent a total absence of accountability. In our case, networked arrangements can be seen as a boon for accountability. Our grounded approach provides us the evidence to make theoretical generalizations (rather than statistical generalizations) and NG appears to offer civil society actors an entrée to decision-making processes previously under sole jurisdiction of the state. In so far as networked arrangements prompt states and international organizations to take the concerns of non-state actors seriously, they are innovative in the face of the failures of state-led governance. This, our research suggests, contributes to an overall net gain in accountability.

\section{Acknowledgements}

We acknowledge the constructive comments received on this paper at the Igth International Symposium for Society and Resource Management. Fieldwork was conducted through the gracious support of the Center for Collaborative Conservation, the US Foreste Service Rocky Mountain Research Station and Lubrecht Experimental Forest, University of Montana. We would like to thank these supporting organizations for their generous support. We are also indebted to our anonymous reviewers for their thorough comments.

\section{References}

Andridge RR, Little RJ. 20IO. A review of hot deck imputation for survey non-response. International Statistical Review 78(I): 40-64.

Armitage DR, Plummer R, Berkes F, Arthur RI, Charles AT, Davidson-Hunt IJ, Diduck AP, Doubleday NC, Johnson DS, Marschke M, McConney P, Pinkerton EW, Wollenberg EK. 2009. Adaptive co-management for social-ecological complexity. Frontiers in Ecology and the Environment 7(2): 95-102.

Bastian M, Heymann S, Jacomy M. 2009. Gephi: an open source software for exploring and manipulating networks. In International AAAI Conference on Weblogs and Social Media. Available at: https://www.aaai.org/ocs/index.php/ICWSM/o9/paper/view/I54/I009 [I3 November 20I4].

Bellotti E. 20I4. Qualitative Networks: Mixed Methods in Sociological Research. Taylor \& Francis: Abingdon, UK.

Benner T, Reinicke W, Witte JM. 2004. Multisectoral networks in global governance: towards a pluralistic system of accountability. Government and Opposition 39(2): I9I-210.

Berkes FJ, Colding J, Folke C. 2003. Navigating Social-Ecological Systems: Building Resilience for Complexity and Change. Cambridge University Press: Cambridge, UK.

Berkes F. 2004. Rethinking community-based conservation. Conservation Biology I8(3): 62I-630.

Betsill MM, Bulkeley H. 2006. Cities and the multilevel governance of global climate change. Global Governance I2(2): I4I-I59.

Biermann F, Betsill MM, Gupta J, Kanie N, Lebel L, Liverman D, Schroeder H, Siebenhüner B, Zondervan R. 2oIo. Earth System Governance: a research framework. International Environmental Agreements: Politics, Law and Economics Io(4): 277-298.

Biermann F, Gupta A. 20II. Accountability and legitimacy in Earth System Governance: a research framework. Ecological Economics 70(II): I856-I864.

Biermann F, Pattberg P, van Asselt H, Zelli F. 2009. The fragmentation of global governance architectures: a framework for analysis. Global Environmental Politics 9(4): 14-40.

Bixler RP, Taylor PL. 20I2. Toward a community of innovation in community-based natural resource management: insights from open source software. Human Organization 3: 234-243.

Bixler RP. 20I4. From community forest management to polycentric governance: assessing evidence from the bottom up. Society and Natural Resources 27(2): I55-I69.

Blondel VD, Cuillaume JL, Lambiotte R, Lefebvre E. 2008. Fast unfolding of communities in large networks. Journal of Statistical Mechanics: Theory and Experiment io: 10008.

Bodin Ö, Crona BI. 2009. The role of social networks in natural resource governance: what relational patterns make a difference?. Global Environmental Change 19(3): 366-374.

Bodin Ö, Prell C. 20II. Social Networks and Natural Resource Management: Uncovering the Social Fabric of Environmental Governance. Cambridge University Press: Cambridge, UK.

Borgatti SP, Molina JL. 2003. Ethnical and strategic issues in organizational social network analysis. Journal of Applied Behavioral Science 39: 337-349.

Brandes U. 200I. A faster algorithm for betweenness centrality. Journal of Mathematical Sociology 25(2): I63-I77.

Büchel B, Raub S. 2002. Building knowledge-creating value networks. European Management Journal 20(6): 587-596.

Burt RS. I987. A note on missing network data in the general social survey. Social Networks 9(I): 63-73.

Burt RS. 2005. Brokerage and Closure: an Introduction to Social Capital. Oxford University Press: Oxford.

Carlsson L, Berkes F. 2005. Co-management: concepts and methodological implications. Journal of Environmental Management 75(I): 65-76. 
Carlsson L, Sandstrom A. 2008. Network governance of the commons. International Journal of the Commons 2(I): 33-54.

Charmaz K. 2006. Constructing Grounded Theory: a Practical Guide Through Qualitative Analysis. Sage Publications: Thousand Oaks, CA.

Creswell JW. I998. Qualitative inquiry and research design: Choosing among five traditions. Sage Publications: Thousand Oaks, CA.

Crona B, Parker JN. 20I2. Learning in support of governance: theories, methods, and a framework to assess how bridging organizations contribute to adaptive resource governance. Ecology and Society I7(I): 32.

Cross JE, Dickmann E, Newman-Gonchar R, Fagan JM. 2009. Using mixed-method design and network analysis to measure development of interagency collaboration. American Journal of Evaluation 30(3): 310-329.

Dietz TE, Ostrom E, Stern PC. 2003. The struggle to govern the commons. Science 302(5652): 1907-I9I2.

Dryzek JS. I999. Transnational democracy. Journal of Political Philosophy 7(I): 30-5I.

Folke C, Hahn T, Olsson P, Norberg J. 2005. Adaptive governance of social-ecological systems. Annual Review of Environment and Resources 30(I): $44 \mathrm{I}-473$.

Freeman LC. I979. Centrality in social networks. Social Networks I: II2-II5.

Galaz V, Österblom H, Bodin Ö, Crona B. 20I4. Global networks and global change-induced tipping points. International Environmental Agreements: Politics, Law and Economics (May): I-33.

Grant RW, Keohane RO. 2005. Accountability and abuses of power in world politics. American Political Science Review 99(I): 29-43.

Imperial MT. 2005. Collaboration and performance measurement: lessons from three watershed governance efforts. In Managing for Results Kamensky JM, Morales A (eds). Rowman and Littlefield Publishers: Lanham, MD; 379-424.

Jordan A. 2008. The governance of sustainable development: taking stock and looking forwards. Environment and Planning C: Government and Policy 26(I): I7-33.

Keen M, Brown VA, Dyball R. 2005. Social Learning in Environmental Management: Towards a Sustainable Future. Earthscan Publications: London.

Knoke D, Burt R. I983. Prominence. In Applied Network Analysis: A Methodological Introduction Burt R, Miner MJ (eds). Sage Publications: Beverly Hills, CA; I95-222.

Knoke D, Yang S. 2008. Social Network Analysis. Sage Publications: Thousand Oaks, CA.

Koppenjan JFM, Klijn EH. 2004. Managing Uncertainties in Networks. A Network Approach to Problem Solving and Decision-Making. Routledge: London.

Kossinetts G. 2006. Effects of missing data in social networks. Social Networks 28(3): 247-268.

Kraatz MS. I998. Learning by association? Interorganizational networks and adaptation to environmental change. Academy of Management Literature $4 \mathrm{I}(6)$ : $62 \mathrm{I}-643$.

Lewis JM. 20II. The future of network governance research: strength in diversity and synthesis. Public Administration 89(4): I22I-I234.

Long JC, Cunningham FC, Braithwaite J. 20I3. Bridges, brokers and boundary spanners in collaborative networks: a systematic review. BMC Health Services Research 13: 158.

Mason M. 2005. The New Accountability: Environmental Responsibility Across Borders. Earthscan Publications: London.

Mason M. 2008. Transparency for whom? Information disclosure and power in global environmental governance. Global Environmental Politics 8 (2): $8-\mathrm{I} 3$.

McKinney M. 20II. Realigning Democratic Practices in Natural Resource Policy: From Vision to Action. Prepared for the Kettering Foundation by the Center for Natural Resources \& Environmental Policy, The University of Montana: Missoula, MT.

Mitchell RB. 20I3. Oran Young and international institutions. International Environmental Agreements: Politics, Law and Economics I3(I): I-I4.

Newig J, Gunther D, Pahl-Wostl C. 20I0. Synapses in the network: learning in governance networks in the context of environmental management. Ecology and Society I5(4): 24.

Newman MEJ. 2006. Modularity and community structure in networks. Proceedings of the National Academy of Sciences of the United States of America го3(23): 8577-8582.

Olsson P, Folke C, Berkes F. 2004. Adaptive comanagement for building resilience in social-ecological systems. Environmental Management 34(I): 75-90.

Ostrom E. 20I0. Beyond markets and states: polycentric governance of complex economic systems. American Economic Review Ioo(June): $64 \mathrm{I}-672$.

Pfeffer J, Salancik GR. I978. The External Control of Organizations: A Resource Dependency Perspective. Harper \& Row: New York.

Powell WW. I990. Neither market nor hierarchy: network forms of organization. In Research in Organizational Behavior (I2) Staw BM, Cummings LL (eds). JAI Press: Greenwich, CT; 295-336.

Prato T, Fagre DB. 2007. Sustaining Rocky Mountain Landscapes: Science, Policy, and Management for the Crown of the Continent Ecosystem. Resources for the Future Press: Washington, DC.

Rhodes RAW. I996. The new governance: governing without government. Political Studies 44: 652-667.

Risse T. 2006. Transnational governance and legitimacy. In Governance and Democracy: Comparing National, European and International Experiences Benz A, Papadopoulos I (eds). Routledge: New York/ECPR Studies.

Robins GL, Bates L, Pattison P. 20II. Network governance and environmental management: conflict and cooperation. Public Administration 89(4): I293-I3I3.

Rosenau J. 2002. Governance in a new global order. In Governing Globalization: Power, Authority and Global Governance McGrew A, Held D (eds). Polity: London; 70-86.

Roundtable on the Crown of the Continent. 20II. http://www.crownroundtable.org [I3 November 20I4].

Sandström A, Crona B, Bodin Ö. 20I4. Legitimacy in co-management: the impact of preexisting structures, social networks and governance strategies. Environmental Policy and Governance 24(I): 60-76. 
Scarlett L, McKinney M, Bixler RP (eds). Forthcoming. Network governance in large landscape conservation: Special Issue: Frontiers in Ecology and Environment, in press.

Strauss A, Corbin J. I998. Basics of Qualitative Research: Grounded Theory Procedures and Techniques. Sage Publications: London.

van Bueren EM, Klijn EH, Koppenjan JFM. 2003. Dealing with wicked problems in networks: analyzing an environmental debate from a network perspective. Journal of Public Administration Research and Theory I3(2): 193-2I2.

Wasserman S, Faust K. I994. Social Network Analysis: Methods and Applications. Cambridge University Press: New York.

Wyborn C. 20I4. Cross-scale linkages in connectivity conservation: adaptive governance challenges in spatially distributed networks. Environmental Policy and Governance, in press.

Wyborn C, Bixler RP. 20I3. Collaboration and nested governance: scale dependency, scale framing, and cross-scale interactions in collaborative conservation. Journal of Environmental Management I23(I5 July): 58-67.

Yin RK. 2003. Case Study Research, Design, and Methods. Sage Publications: Thousand Oaks, CA.

Young O. 2002. The Institutional Dimensions of Environmental Change: Fit, Interplay, Scale. MIT Press: Cambridge, MA.

Zelli F, van Asselt H. 20II. The fragmentation of global climate governance and its consequences across scales: the case of REDD. In ECPR General Conference, Reykjavik, Iceland. 